\title{
Ampliando
}

Entre Blow Up de Antonioni y el Cementerio de las Cenizas del Pensamiento de John Hejduk

\section{Blowing Up}

Between Blow Up by Antonioni and Cemetery of Ashes of Thought by John Hejduk

Carlos Barberá Pastor

Universidad de Alicante

carlos.barbera@gcloud.ua.es 
La visión que Thomas tiene del mundo es a través de su cámara. Concibe la realidad mediante la imagen fotográfica. El glamour de los años 60 en Londres es su forma de vida y la concepción de aquello que le rodea es desde un marco que permite entenderlo todo a través de un objetivo ocular. A partir de ahí construye su visión de las cosas. La réflex que guarda en la guantera de su Rolls Royce descapotable da a entender cómo ve las cosas desde la fotografía, su coche, el estudio y sus colaboradoras. Aunque Thomas se adentre en el ámbito del mundo obrero, su visión del trabajador es el de la imagen del trabajador fotografiado. La ciudad, las protestas, o las juergas de jóvenes liberados, muestran acontecimientos que parecen ser construidos para él; donde las calles, las fachadas de las viviendas, los árboles de los parques, el interior de una fábrica o la hierba desde donde las palomas inician el vuelo, son escenas para sus fotografías. Es algo parecido a, que, por el hecho de fotografiar un objeto eso mismo que inmortaliza le perteneciera. Es su visión a través de la imagen fotográfica quien retroalimenta su construcción del mundo. Lo que él decide enmarcar forma parte de su dominio según lo concibe a partir de la imagen reproducida. El mundo se convierte en idílico porque todo lo que ve lo mira a través de cómo él quiere que aparezca. El medio es la fotografía. Es por lo que Thomas tiene éxito. Él define las cosas desde el encanto y la sensualidad que exclusivamente quiere mostrar.

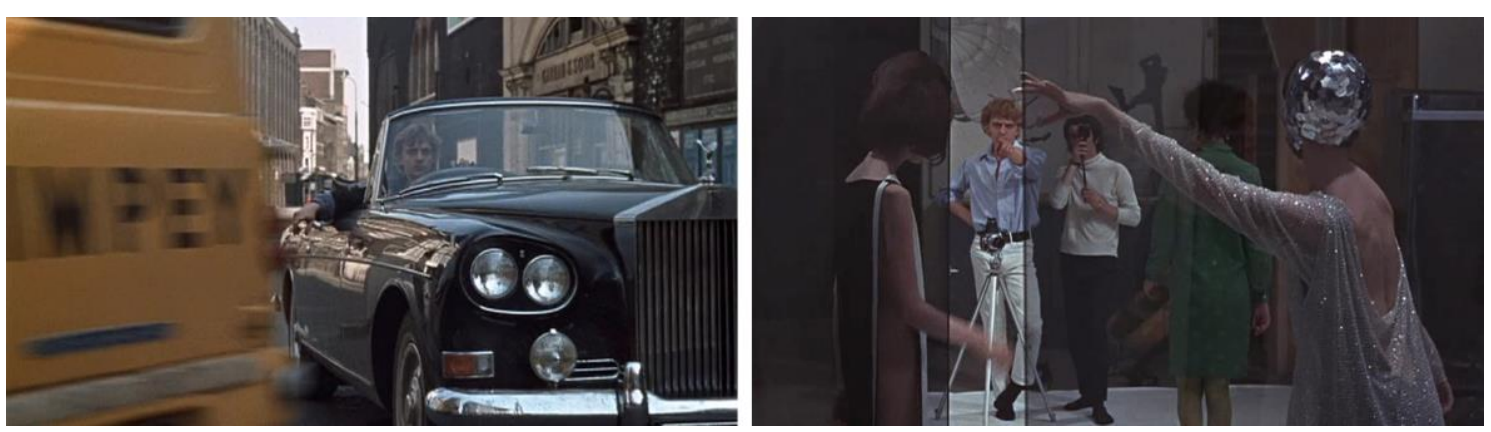

Imagen 1. Thomas en su Rolls Royce descapotable. Fotograma de la película Blow Up de Michelangelo Antonioni. Imagen 2. Thomas en su estudio de fotografía. Fotograma de la película Blow Up.
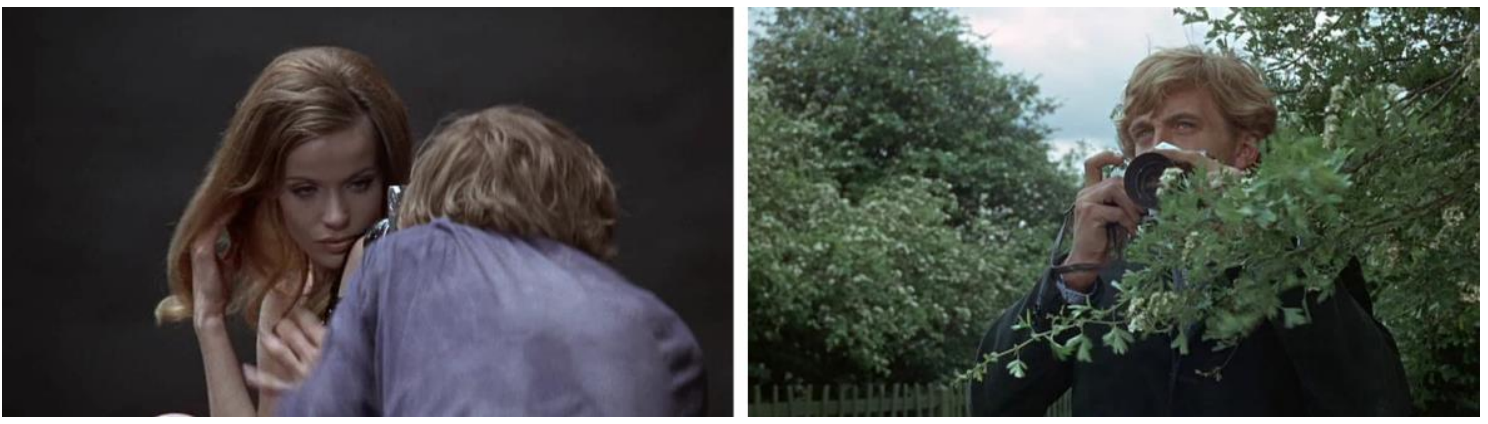

Imagen 3. Thomas fotografiando a una modelo. Fotograma de la película Blow Up.

Imagen 4.. Thomas en Maryon Park. Fotograma de la película Blow Up.

Cuando Thomas decide pasear por Maryon Park, los saltos que da de felicidad son por encontrarse en una escenografía propia de su ámbito, de su intervención. El lugar va a ser transformado según él lo ve, por ello se muestra eufórico. Los matorrales y los árboles son el fondo de las escenas que desea construir, el de una pareja besándose. La mujer 
fotografiada, Vanessa Redgrave, intercede para no ser retratada, pero Thomas no va a permitir que nadie estropee su propia construcción del parque.

Ese mismo día, una vez las fotografías son ampliadas, aparece algo impensable. Al aumentar una y otra vez lo revelado, tras la espesura, una mano sujeta una pistola apuntando a una de las personas que él fotografía. Justamente en ese momento, al surgir lo imprevisto al margen de sus pretensiones, todo cambia. Se desmorona su construcción. Algo fuera de sus registros emerge en la propia imagen fotográfica. Al no estar previsto que el asesino aparezca tras los fondos que él mismo precisa, la sombra, por detrás de la escenografía, pondrá en entredicho su construcción de lo visible. Tras la imagen, repentinamente, uno de tantos misterios de nuestra estructura social y que ninguno de sus anteriores trabajos fue capaz de comunicar se le presenta sin apenas preverlo. El aturdimiento le lleva a observar de otro modo, como nunca lo había hecho antes. Desenmascara una nueva condición de mirar la fotografía. Es justamente aquello que no controla lo que revela y le hace descubrir una enigmática manera de ver, que posiblemente nunca había experimentado. La imagen construida por él, hasta ese momento, no le permitía percibir aquello que, en ese instante, le conmociona, le descontrola y ofusca.

La sensación que produce mirar, expresado por él mismo cuando la filmación de la película de Antonioni le enfoca constantemente, muestra la sorpresa de darse cuenta que tras la contemplación puede encontrarse un criminal. Thomas, cuando divulga la situación al sentir por primera vez tal conmoción, se encuentra apartado de todo lo que hasta ese momento le acompañaba. Ahí, es donde parece que su expresión desvela la importancia que tiene esta nueva relación con la fotografía y con lo que es fotografiado por él, apartándole de su manera de entender las cosas.
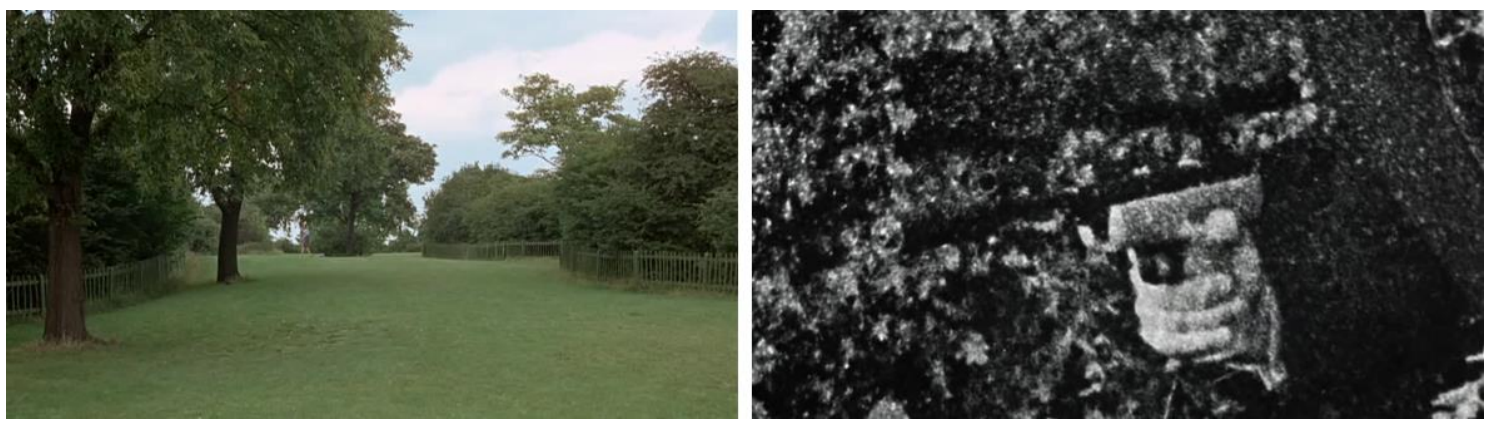

Imagen 5. Maryon Park. Fotograma de la película Blow Up.

Imagen 6. Pistola apuntando entre la espesura del parque. Fotogramas de la película Blow Up.
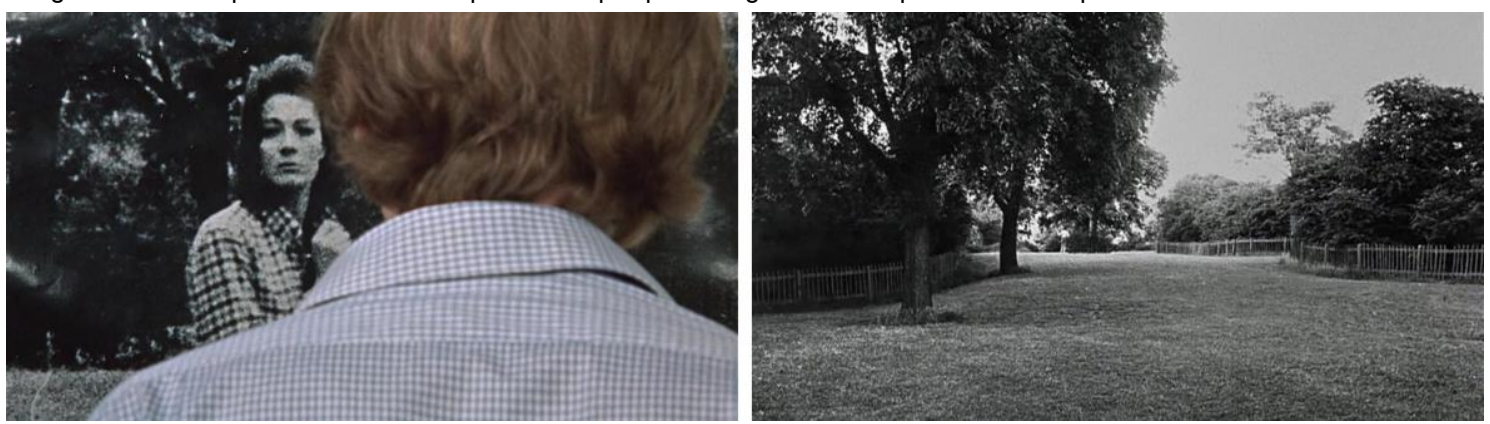

Imagen 7. Thomas enfrentado a la actriz Vanessa Redgrave, Fotograma de la película Blow Up.

Imagen 8. Fotografía del Maryon Park. Fotograma de la película Blow Up.. 
II

Las palabras Blow Up aparecen escritas entremedio de una de las láminas del trabajo titulado Fabrications de John Hejduk. En referencia al misterio que esconde la imagen como la que presenta la película Blow $U p$, casi toda la obra del arquitecto americano se refiere a la dualidad que hay entre el objeto diseñado y el sujeto que lo utiliza. Las propuestas que desarrolla a partir de los años 50, hasta el año 2000, desde las Texas Houses hasta las Masques, aluden a aquello que es presentado y a aquello que hay detrás de lo propiamente figurativo. Sobre esto mismo, Hejduk manifiesta en un texto de Mask of Medusa una referencia a la casa La Roche de Le Corbusier en la que dice: "Hace unas semanas, un arquitecto indio vino a visitarme. Había leído alguno de mis escritos. Alguien le había contado sobre mis experiencias en la casa La Roche y mi interpretación de ella. Entonces vino a visitarme. Me contó una historia sobre lo que hace que la arquitectura sea intensa. «Hay dos personas en un barco mirando hacia el tranquilo océano. Enfrentados solos ante el crepúsculo de la tarde en un mar en calma, de repente, sale la aleta de un tiburón. Quizás, solamente por unos segundos. Entonces la aleta se esconde. Ante esto, ambos hombres quedan aterrorizados.» $\mathrm{Al}$ arquitecto Correa se le ocurrió que toda gran obra de arquitectura como La Roche tiene bajo su superficie de calma, monstruos. En las profundidades de lo volumétrico, los monstruos están ahí abajo. Algunas de las mejores arquitecturas del mundo tienen ese aspecto. Sin embargo, él no llegó a entender esto hasta que no comprendió mi lectura de La Roche, sobre qué matices esconde el programa. La Casa La Roche es una casa doble, la otra es la Casa Jeanneret. El Dr. Blanche fue, creo, un médico del siglo XIX que dirigió un asilo para personas con trastornos mentales. Era una figura cultural muy respetada que fue mencionada por Cocteau y de Maupassant. Creo que Proust lo menciona también. Gloria (mi mujer) descubrió todo esto."

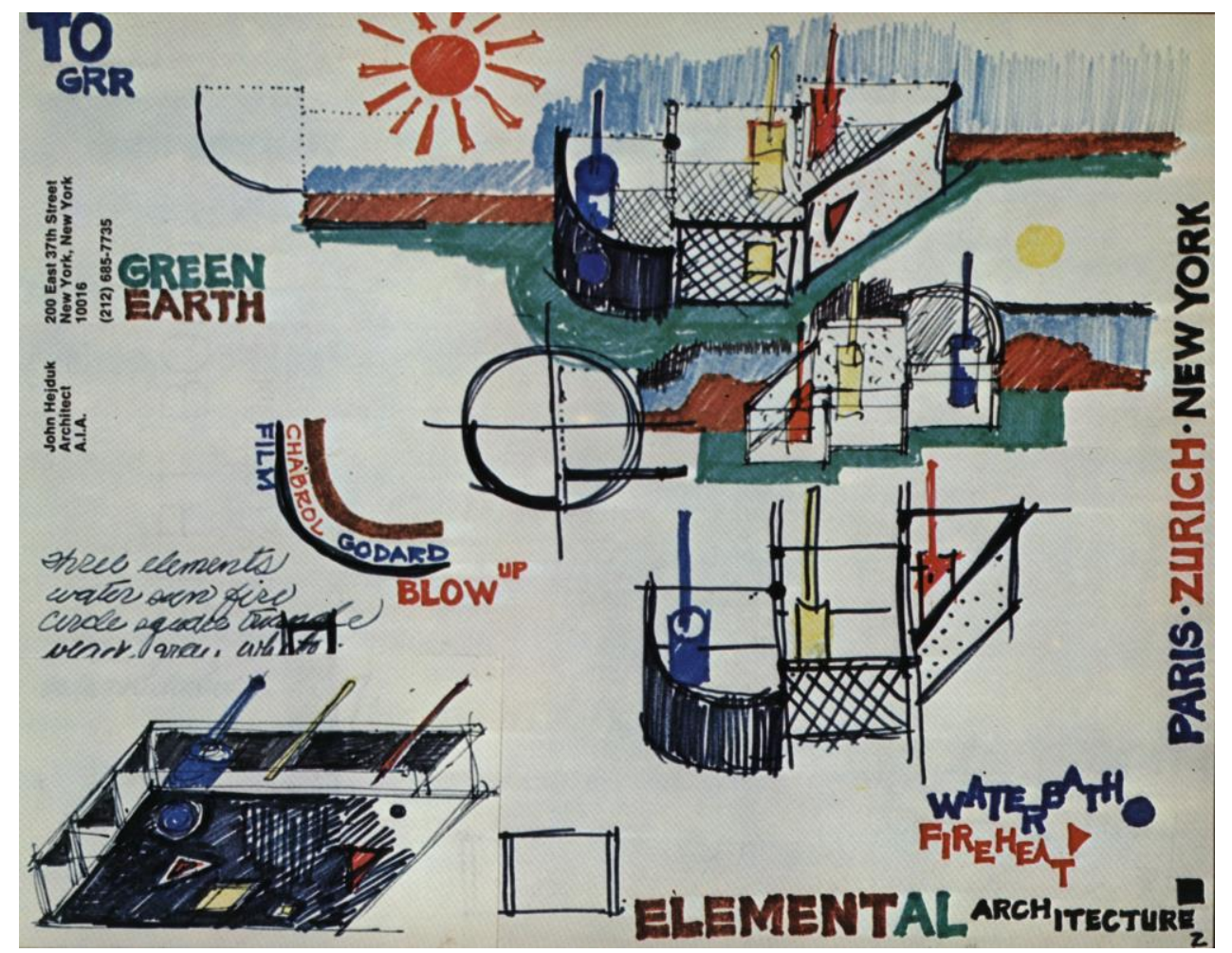

Imagen 9. Fabrications de John Hejduk. 
III

La arquitectura, y la educación del arquitecto, han establecido una especie de mirada que ha conformado una visión del mundo según la construcción de la escena arquitectónica. El poder tan seductor que tiene y ha tenido la arquitectura, cuando el primer sentido del cuerpo que permite entablar una relación con ella es la visión, ha planteado que su forma visual subordine - en muchos casos- el uso, el programa, la intencionalidad o los contenidos del espacio. El diseño, la elaboración del proyecto, el detalle constructivo, la técnica, el dibujo, o su ubicación, ha sido, y sigue siendo, el principal aliciente para el arquitecto, que trata de definir su mirada a partir de una propuesta donde pocas veces la intencionalidad trata de hacer ver otros ámbitos, como el sociológico, el psicológico, el filosófico o el político. Todas las condiciones propias de la arquitectura que muestra el arquitecto no es que no sean importantes, que lo son, sino que, más bien, cuando sirven para subordinar y esconder la razón por la cual una pieza ocupa una posición y no otra, la arquitectura entabla una actitud de pantomima que acabará desenmascarándose en el tiempo. Han tenido que pasar 60 años para que Josep Quetglas desvele qué hay tras el Pabellón de Alemania de Mies van der Rohe en Barcelona -la edición canadiense de Imágenes del Pabellón de Alemania es de 1991 y la última, El horror cristalizado de ediciones asimétricas, de 2019-. Así, pasa con innumerables obras. La E-1027, la Malaparte, la casa Huarte, la Villa Savoye, la casa Kaufmann, la Villa Rotonda, el Museo Sir John Soane,... y así. Se podría no parar. Son innumerables las obras que se caracterizan por una doble mirada que ofuscan a quienes las investigan. La contemplación domesticada del idílico espacio arquitectónico aparentemente en calma, en la mayoría de casos, contrasta con acontecimientos, usos e intencionalidades que llevan a ver de un modo que nunca habíamos podido ver e imaginar esa misma arquitectura. En algunos casos supedita todo lo dicho sobre ella.

Las propuestas de John Hejduk desvelan la particularidad de la doble cara entre la apariencia y el acontecimiento. Es propuesto, no solo, en la medida de presentar esta situación como comenta para la casa La Roche, sino en sus propias obras, exteriorizando y mostrando esa doble presencia que es manifiesta de numerosas maneras.

La Casa del Habitante que se negó a Participar, la New England Masque, Berlin Masque, Víctims, Riga, Lancaster Hanover Masque, el Cementerio de las Cenizas de Pintores de Bodegones, la Casa en el laberinto, el Santuario, la Iglesia, el Baptisterio, entre tantas y tantas otras obras propuestas y desarrolladas en menos de 20 años, plantean una construcción del mundo desde el protagonismo que tiene el habitante que las utiliza. Sin embargo, ninguna obra construida de John Hejduk, exceptuando yo creo, el Centro Socio Cultural de A Trista en Santiago de Compostela o la Escuela de la Cooper Union en Nueva York, ha sido erigida para ser habitada.

\section{IV}

Según dice John Hejduk, cuando una persona observa una pintura y se mantiene distanciada entre metro y medio y 4 metros del cuadro, en el momento que el observador conecta totalmente con la lámina, la distancia real y apreciable que hay entre ellos desaparece. El pensamiento, según dice, ilumina el aire que hay entre la superficie de los pigmentos de la pintura y el observador. Se conforma una coexistencia entre el pensa- 
miento físico presentado mediante el cuadro y el pensamiento desmaterializado y puro del espectador. Es el momento que se convierten en una misma cosa lo material y lo inmaterial a través de la distancia. "El resultado es una revelación." John Berger dice algo parecido al respecto. Podríamos decir, según Hejduk, que el pensamiento del observador sale del cuerpo, cruza el espacio que hay entre sus ojos y el lienzo, y absorbe la separación que hay entre el sujeto y el objeto para transformarse en una misma cosa, por así decirlo. La clarividencia desmaterializada que abandona el cuerpo del observador hace desaparecer el espacio entre ellos, como si el pensamiento saliera mediante un vuelo sin materia que colapsa la distancia. Entre la materia de pigmentos de la que se compone el lienzo, y el sujeto que la observa, el espacio entre ellos desaparece convirtiéndose objeto y sujeto en una misma cosa. Esta fusión, transformadora, es la que debería llevar al investigador de arquitectura a conformar una densa unión entre el dibujo arquitectónico y sus sentimientos. Hejduk propone que se esta situación entre sujeto y objeto y quede manifiesta mediante sus Masques.

\section{V}

En el Cementerio de las Cenizas del Pensamiento, un proyecto para Venecia de 1974 en el que junto a él se ubicó la Wall House 3, también de 1974, John Hejduk propone un lugar que aloje las cenizas de las grandes obras de literatura desarrolladas durante toda la historia de la humanidad. En cierta manera, Hejduk plantea mostrar los restos, exponer las cenizas desde el sentido que supone el olvido y el declive de la cultura occidental. El visitante se enfrenta al título del libro y al nombre de su autor junto a las cenizas, de forma que, si uno ha leído Moby Dick de Herman Melville, por ejemplo, no solamente leerá muy lentamente las sílabas del título y su autor, sino que entre ellos desaparecerá la distancia cuando la memoria recupere las palabras escritas de lo leído, revelando en el espacio entre objeto y sujeto un contenido. La distancia entre una caja de cenizas y el visitante, aunque sea muy corta, entre menos de medio metro y un metro, puede unir o distanciar hasta el infinito.

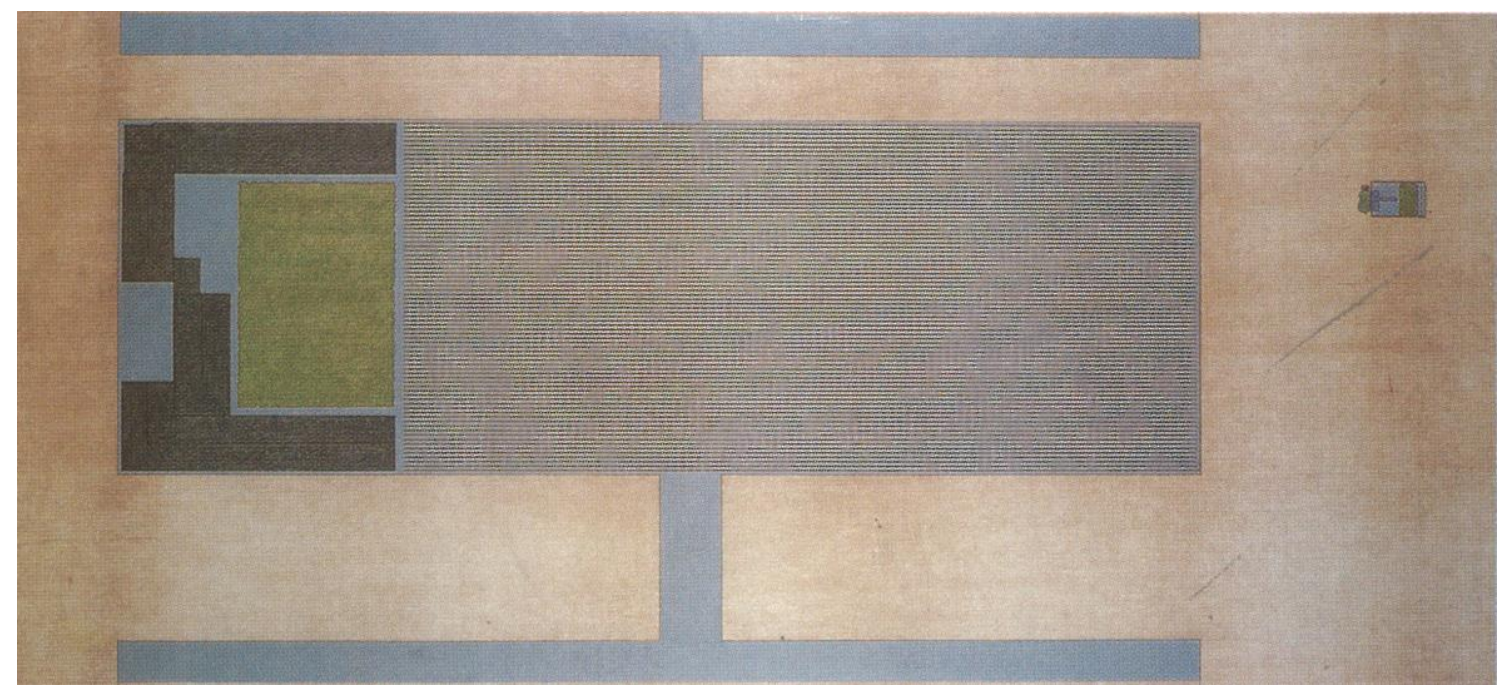

Imagen 9. El Cementerio de las Cenizas del Pensamiento y la Wall House 3. 


\section{EPÍLOGO}

Si el escrito está numerado no es para ordenar los capítulos, sino, más bien, para desordenarlos. Si empezaste por el 1 y acabaste por el epílogo, la próxima vez hazlo al revés, y la siguiente empieza por el 2, sigue con el 4, y luego, el 1, el 5 y el 3. En este estado el epílogo no lo leas. La cuarta vez puedes dejar de leerlo, volver a empezar, o leerlos aleatoriamente. 